\title{
A REVIEW ON “NEW TREATMENT STRATEGIES FOR ALZHEIMER'S DISEASE AS NEURODEGENERATIVE DISEASE AND ITS RISK FACTOR CAUSE, SYMPTOMS, AND TREATMENT AT WORLDWIDE"
}

\author{
ROHIT JAYSING BHOR* \\ Department of Pharmaceutical Chemistry, PRES's College of Pharmacy Chincholi, Sinner, Nasik - 422 103, Maharashtra, India. \\ Email: rohit.bhor69@gmail.com
}

Received: 19 July 2016, Revised and Accepted: 29 August 2016

\begin{abstract}
Alzheimer's disease (AD) is a dynamic and irreversible neurodegenerative illness and relates to the most widely recognized reason for dementia around the world. AD is a dynamic and lethal cerebrum ailment. Alzheimer's obliterates mind cells, bringing on memory issue or misfortune and issues with speculation and conduct sufficiently serious to influence work, long lasting leisure activities or social life. Alzheimer's illness is quickly becoming worldwide, but there is no cure for it. Now, accessible medications just give symptomatic help and do not mediate in infection prepare adequately enough to avert or cure it. Various late studies have reported that working memory does not appear to demonstrate regular age-related deficiencies in solid more established grown-ups when enthusiastic data are included. Indeed, contingent upon the capacity included, patients might demonstrate an enthusiastic advantage in their working memory execution. Moreover, this advantage is not generally obviously one-sided (e.g., toward negative or positive data). We decipher this intricate example of results as an outcome of the cooperation between numerous components including the seriousness of $\mathrm{AD}$, the nature of emotional jolts, and sort of working memory errand. Clinical advantages of the accessible pharmacological treatment for AD with antidementia drugs (to be specific cholinesterase inhibitors and Memantine) are obvious. In an unexpected way, learns about the transient capacity to encode and effectively control enthusiastic data in dementia of Alzheimer's sort are few and have yielded blended results.
\end{abstract}

Keywords: Alzheimer's disease, Risk factor for Alzheimer's disease, Diagnosis, Classification of Anti-Alzheimer's drug.

(C) 2016 The Authors. Published by Innovare Academic Sciences Pvt Ltd. This is an open access article under the CC BY license (http://creativecommons. org/licenses/by/4. 0/) DOI: http://dx.doi.org/10.22159/ajpcr.2016.v9s3.14196

\section{INTRODUCTION}

Alzheimer's disease (AD) is otherwise called Alzheimer infection or Alzheimer's. Alzheimer's sickness is a case of unending neurodegenerative malady. It is the reason for $60 \%$ to $70 \%$ of instances of dementia. The most widely recognized early side effect is fleeting memory misfortune. This illness begins gradually and deteriorates after some time [1]. Most normal side effects of this illness are fleeting memory misfortune, issue with dialect, bewilderment, state of mind swings, loss of inspiration, not overseeing self-consideration, and conduct changes [2]. Alzheimer's ailment gives side effects such as issue with dialect, loss of inspiration, not overseeing self-consideration, behavioral changes, and temperament swings. The reason for Alzheimer's sickness is ineffectively caught on. Around $70 \%$ of the danger is accepted to be hereditary with numerous qualities generally included. Other danger variables incorporate a background marked by head wounds, wretchedness, and hypertension. In 2015, there were roughly 48 million individuals worldwide with Alzheimer's malady [3] It regularly starts in individuals more than 65 years old, in spite of the fact that $4-5 \%$ of cases are early onset of Alzheimer's ailment which starts before this. It influences around $6 \%$ of individuals 65 years and more seasoned. In 2010, Alzheimer's sickness brought about around 486,000 passing. This Alzheimer malady was recognized by the German researcher or psychiatric Alois Alzheimer in 1901 [4]. In the $20^{\text {th }}$ century, the determination of Alzheimer's ailment was done between the ages of 45 and 65 years. The reason for this malady is ineffectively comprehended or not known. For Alzheimer's infection, other danger element may incorporate head wounds, sorrow, hypertension, and hereditary issue [5]. The danger of Alzheimer's illness was diminished by controlling or diminishing stoutness and by mental and physical activity [6]. There is no solution or supplement that control or lessening hazard. Individuals influenced by Alzheimer's ailment in 2010 are between 21 and 35 million, the greater part of the general population more than 65 years old, $4-5 \%$ of cases are earlyonset Alzheimer's. Alzheimer's sickness, i.e., promotion is a case of the moderate dynamic ailment of cerebrum [7]. It gives side effects such as impedance of memory and unsettling influences in arranging, dialect, thinking, and observation. This ailment is found after the age of 70, and it influences around half of persons beyond 85 years old. For Alzheimer's illness, fundamental danger component is expanded age. Reason for this ailment is obscure. Alzheimer's sickness likewise gives or cause changes in considering, conduct, and identity. Close family and companion can first notice postulations kind of side effects $[8,9]$. In 2010 , approximately 4.7 million individuals of 65 years old and more seasoned were living with Alzheimer's sickness in the US. Alzheimer's ailment association gives factual report an extent of the populace influenced a little more than a tenth of individuals in the more than 65 age bunch have the infection in the US in 2013 [10-12]. AD is the main source of dementia around the world, influencing more than half of the general number of deranged people, which has been assessed to associate with 24 million over all countries. The pervasiveness of dementia is relied on to further increment in the approaching decades, as a result of the relentless development of maturing populace in both created and creating nations. As indicated by the World Health Organization projections, around $75 \%$ of the evaluated 1.2 billion older folks will live in low and center salary nations by the year 20. Agebalanced appraisals of dementia pervasiveness are high (above 5\%) in most Asian and Latin American Countries. In any case, pervasiveness rates of dementia appear to be lower (1-3\%) in India and sub-Saharan Africa $[13,14]$. Epidemiological studies directed in India somewhere around 1996 and 2006 showed that dementia influences $2.7 \%$ of the populace, $\mathrm{AD}$ being the most widely recognized cause $(1.3 \%)$. It is paramount that these numbers parallel the assessments of dementia and $\mathrm{AD}$ in the Western social orders cut considerably; in any case, the extent of instances of AD among dementia is essentially the same [15]. Methodological reasons should likewise be considered as a conceivable wellspring of predisposition in the past assessments of dementia commonness in India, for example, non-acknowledgment of cases because of restricted access of patients to particular administrations in remote locales, specific evacuation of cases because of early mortality, and socially related challenges to discover the finding of psychological 
hindrance [16]. A late epidemiological study demonstrated that the pervasiveness of dementia and AD in South India (6.44\% and 3.56\%, individually) was really higher than beforehand reported. Moreover, a post-mortem examination-based study showed that the pervasiveness of $\mathrm{AD}$ pathology in India was like that seeing in created nations. Contemplates have likewise recommended dissimilarities in the common course of the ailment in India when contrasted with western nations. As a feature of the Indo-US study, Chandra et al. reported a lower middle survival time after the onset of side effects of patients with $\mathrm{AD}$ in India when contrasted with created nations [17]. Potential reasons for this shorter future of $\mathrm{AD}$ patients are intricate and might be auxiliary to insufficient general well-being help developing dementia care; however, other social, ecological, and natural variables might be related to a quicker course of the ailment. Advertisement patients in India may have fundamentally more fancies, pipedreams, and tension and mind-set indications over the span of dementia [18-20]. The most recent 10 years have seen a huge development in examination on early identification. This exploration impelled the 2011 production of proposed new analytic criteria and rules for Alzheimer's sickness. Under the proposed criteria, the ailment starts before side effects, for example, memory misfortune show up, while prior criteria require memory misfortune and a decrease in speculation capacities for an Alzheimer's analysis to be made. Since experimental assessment of the proposed criteria is continuous, "Alzheimer's sickness" in this report alludes to the malady as characterized by the before criteria.

\section{HISTORY}

Alzheimer's ailment was not until 1901 that German Psychiatrist Alois Alzheimer. Alzheimer was distinguished what got to be known as Alzheimer's infection in a 50-year-old lady, he called Auguste Deter quiet $[21,22]$ (Fig. 1). Auguste Deter patient was kicked the bucket in 1906. Alzheimer's illness was initially depicted as an unmistakable malady by the researcher Emil Kraepelin after clinical (dreams and fantasies) and obsessive components. For the greater part of the $20^{\text {th }}$ century, the conclusion of Alzheimer's malady was saved for people between the ages of 45 and 65 who created manifestations of dementia. This inevitably prompted the determination of Alzheimer's ailment autonomous of age. Phases of this current Alzheimer's infection can be ordered on the premise of indications. It incorporates taking after stages like (Table 1):

a. Mild AD

b. Moderate $\mathrm{AD}$

c. Severe AD.

\section{Mild AD}

Mellow Alzheimer's sickness gives side effects such as new circumstances, moderated learning capacity, postponed responses, begins talking more gradually than before, misguided thinking and settling on wrong choices, disposition swings and get to be discouraged, touchy, or anxious, memory misfortune, i.e., gentle subjective hindrance.

\section{Moderate AD}

Moderate Alzheimer's ailment gives side effects such as issues perceiving dear loved ones, turns out to be more eager, particularly in late evening and during the evening, and issues perusing, composing, and managing numbers, inconvenience dressing.

\section{Serious or severe AD}

Serious Alzheimer's ailment gives indications such as no more recollect how to bathe, eat, dress, or go to the washroom autonomously, no more knows when to bite and swallow, issue with equalization or strolling and may fall every now and again, more confounded at night, and loses entrails.

\section{SYMPTOMS OF AD}

Symptoms of AD can be analyzed at any phase of Alzheimer's dementia. It gives side effects which can mistake for both a patient and the general population around them $[23,24]$. The most widely recognized

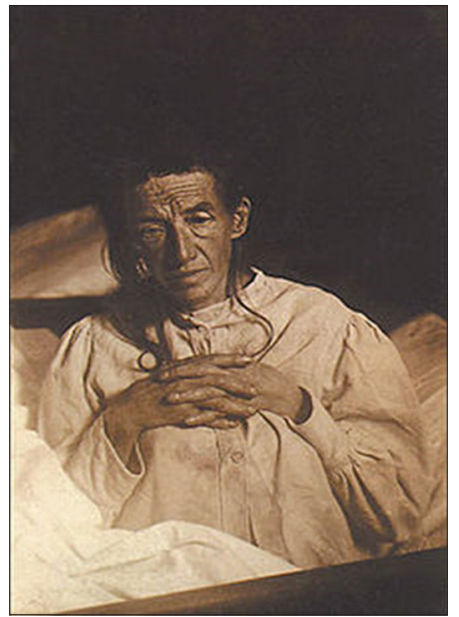

Fig. 1: Auguste Deter patient of Alzheimer's patient in 1902. Auguste Deter was the initially depicted instance of what got to be known as Alzheimer's malady

presentation denoting Alzheimer's dementia is the place side effects of memory misfortune. Some rule was created by the National Institute on Aging and the Alzheimer's Association, in this rule no less than 2 of the five indication range recorded beneath (Table 2):

1. Memory loss that disrupts daily life: One of the most well-known indications of Alzheimer's is memory misfortune, particularly overlooking as of late learned data. Others incorporate overlooking critical dates or occasions; requesting the same data again and again; depending on memory helpers (e.g., update notes or electronic gadgets) or relatives for things they used to handle all alone.

2. Challenges in planning or solving problems: Some individuals may encounter changes in their capacity to create and take after an arrangement or work with numbers. They may experience difficulty taking after a recognizable formula or monitoring month-to-month bills. They may experience issues thinking and take any longer to do things than they did some time recently.

3. Difficulty completing familiar tasks at home, at work, or at leisure: People with Alzheimer's frequently think that it is difficult to finish everyday undertakings. At times, individuals may experience difficulty heading to a natural area, dealing with a financial plan at work, or recollecting the standards of a most loved diversion.

4. Confusion with time or place: People with Alzheimer's can forget about dates, seasons, and the progression of time. They may experience difficulty understanding something in the event that it is not happening promptly. Once in a while, they may overlook where they are or how they arrived.

5. Trouble understanding visual images and spatial relationships: For a few people, having vision issues is an indication of Alzheimer's. They may experience issues perusing, judging separation, and deciding shading or differentiation. As far as discernment, they may pass a mirror and think another person is in the room. They may not understand they are the individual in the mirror.

6. New problems with words in speaking or writing: People with Alzheimer's may experience difficulty taking after or joining a discussion. They may stop amidst a discussion and have no clue how to proceed or they may rehash themselves. They may battle with vocabulary, have issues finding the right word or call things by the wrong name (e.g., calling a "watch" a "hand-clock").

7. Misplacing things and losing the ability to retrace steps: A man with Alzheimer's illness may place things in strange spots. They may lose things and be notable about-face over their progressions to discover them once more. Some of the time, they may blame others for taking. This may happen all the more as often as possible after some time.

8. Decreased or poor judgment: Decreased or poor judgment: Decreased or misguided thinking: People with Alzheimer's may encounter 
Table 1: Classification of AD

\begin{tabular}{|c|c|c|c|}
\hline $\begin{array}{l}\text { Effects of aging on memory } \\
\text { but not AD }\end{array}$ & Early stage Alzheimer's & Middle-stage Alzheimer's & Late stage Alzheimer's \\
\hline Forgetting things occasionally & $\begin{array}{l}\text { Not remembering episodes of } \\
\text { forgetfulness }\end{array}$ & $\begin{array}{l}\text { Greater difficulty remembering } \\
\text { recently learned information }\end{array}$ & Poor ability to think \\
\hline Misplacing items sometimes & $\begin{array}{l}\text { Some confusion in situations } \\
\text { outside the familiar }\end{array}$ & Trouble knowing where they are & $\begin{array}{l}\text { Repeats same } \\
\text { conversations }\end{array}$ \\
\hline Not remembering exact details & Forgets names of family or friends & Problems with sleep & Problems speaking \\
\hline Minor short-term memory loss & $\begin{array}{l}\text { Changes may only be noticed by } \\
\text { close friends or relatives }\end{array}$ & $\begin{array}{l}\text { Deepening confusion in many } \\
\text { circumstances }\end{array}$ & $\begin{array}{l}\text { More abusive, anxious, } \\
\text { or paranoid }\end{array}$ \\
\hline
\end{tabular}

AD: Alzheimer's disease

Table 2: Symptoms of Alzheimer disease

\begin{tabular}{|c|c|c|}
\hline S. No. & Symptoms & Examples like \\
\hline 1 & Worsened ability to take in and remember new information & $\begin{array}{l}\text { Repetitive questions or conversations } \\
\text { Misplacing personal belongings } \\
\text { Forgetting events or appointments } \\
\text { Getting lost on a familiar route }\end{array}$ \\
\hline 2 & $\begin{array}{l}\text { Impairments to reasoning, complex tasking, exercising } \\
\text { judgment like }\end{array}$ & $\begin{array}{l}\text { Poor understanding of safety risks } \\
\text { Inability to manage finances } \\
\text { Poor decision-making ability } \\
\text { Inability to plan complex or sequential activities }\end{array}$ \\
\hline 3 & $\begin{array}{l}\text { Impaired visuospatial abilities (but not, for example, due to } \\
\text { eyesight problems): Like }\end{array}$ & $\begin{array}{l}\text { Inability to recognize faces or common objects or to find objects in } \\
\text { direct view } \\
\text { Inability to operate simple implements, or orient clothing to the body }\end{array}$ \\
\hline 4 & Impaired speaking, reading, and writing & $\begin{array}{l}\text { Difficulty thinking of common words while speaking, hesitations } \\
\text { Speech, spelling and writing errors }\end{array}$ \\
\hline 5 & Changes in personality and behavior, for example & $\begin{array}{l}\text { Out-of-character mood changes, including agitation; less interest, } \\
\text { motivation or initiative; apathy; social withdrawal } \\
\text { Loss of empathy } \\
\text { Compulsive, obsessive, or socially unacceptable behavior }\end{array}$ \\
\hline
\end{tabular}

changes in judgment or basic leadership. For instance, they may utilize misguided thinking when managing cash, giving vast adds up to telemarketers. They may give careful consideration to prepping or keeping themselves clean.

9. Withdrawal from work or social activities: A man with Alzheimer's may begin to expel themselves from side interests, social exercises, work ventures, or games. They may experience difficulty staying aware of a most loved games group or recollecting how to finish a most loved side interest. They may likewise abstain from being social due to the progressions they have encountered.

10. Changes in mood and personality: The disposition and identities of individuals with Alzheimer's can change. They can get to be confounded, suspicious, discouraged, frightful, or on edge. They might be effortlessly resentful about home, at work, with companions, or in spots where they are out of their solace zone 1.

\section{RISK FACTOR FOR AD}

Except for the uncommon instances of Alzheimer's created by hereditary transformations, specialists trust that Alzheimer's, as other regular interminable infections, creates as a consequence of different components as opposed to a solitary cause. This segment depicts known danger components for Alzheimer's [25,26]. Different elements that may influence danger are being considered.

\section{Age}

The most dangerous component for Alzheimer's ailment is age. A great many people with Alzheimer's sickness are analyzed at age 65 or more established. Individuals more youthful than 65 can likewise build up the malady, in spite of the fact that this is much rarer (see the prevalence segment). While age is the most dangerous variable, Alzheimer's is not a typical piece of maturing and age alone is not adequate to bring about the ailment. The primary danger component for this malady is expanded age. The recurrence of Alzheimer's sickness is consistently expanded. Just $10 \%$ of individuals more than 65 years old and $50 \%$ of individuals more than $85 \%$ of age have Alzheimer's sickness. New medicines are created for diminishing the building up Alzheimer's infection

\section{Family history}

A family history of Alzheimer's is a bit much for a person to build up the infection. In any case, people who have a guardian, sibling, or sister with Alzheimer's will probably build up the illness than the individuals who do not have a first-degree relative with Alzheimer's. The individuals who have more than one first-degree relative with Alzheimer's are at considerably higher danger. At the point, when illnesses keep running in families, heredity (hereditary qualities), shared natural and way of life components, or both, may assume a part. The expanded danger connected with having a family history of Alzheimer's is not by any means clarified by whether the individual has acquired the APOE-e4 hazard quality.

\section{Mild cognitive impairment (MCI)}

MCI is a condition, in which an individual has mellow yet quantifiable changes in deduction capacities that are detectable to the individual influenced and to relatives and companions, yet do not influence the individual's capacity to complete ordinary exercises. Be that as it may, $\mathrm{MCI}$ does not generally prompt dementia. In a few people, $\mathrm{MCI}$ returns to typical perception or stays stable. In different cases, for example, when a solution causes subjective hindrance, MCI is erroneously analyzed. In this way, it is critical that individuals encountering psychological disability look for help as quickly as time permits for finding and conceivable treatment.

\section{Cardiovascular disease risk factors}

Developing confirmation recommends that the strength of the cerebrum is firmly connected to the general soundness of the heart and veins. The mind is supported by one of the body's wealthiest 
systems of veins. A sound heart guarantees that enough blood is pumped through these veins, and solid veins guarantee that the mind is supplied with the oxygen and supplement rich blood it needs to work ordinarily. Numerous components that build the danger of cardiovascular ailment are additionally connected with a higher danger of dementia. These elements incorporate smoking, weight in midlife, and diabetes.

\section{Education}

Individuals with less years of formal instruction are at higher danger for Alzheimer's and different dementias than those with more years of formal training. A few scientists trust that having more years of training fabricates a "subjective store" that empowers people to better make up for changes in the cerebrum that could bring about side effects of Alzheimer's or another dementia. As indicated by the intellectual store speculation, having more years of instruction expands the associations between neurons in the cerebrum and empowers the mind to make up for the early cerebrum changes of Alzheimer's by utilizing backup ways to go of neuron-to-neuron correspondence to finish a subjective undertaking. A few researchers accept different elements may add to or clarify the expanded danger of dementia among those with lower instructive accomplishment. These elements incorporate will probably have occupations that are less rationally empowering. Likewise, bring down instructive achievement may reflect lower financial status, which may improve one's probability of poor sustenance and lessening one's capacity to manage the cost of medicinal services or get recommended medications.

\section{Social and cognitive engagement}

Extra studies propose that residual socially and rationally dynamic all through life may bolster mind well-being and potentially decrease the danger of Alzheimer's and different dementias. Remaining socially and rationally dynamic may assemble intellectual store, however, the precise component by which this may happen is obscure. More research is expected to better see how social and psychological engagement may influence organic procedures to diminish hazard.

\section{Traumatic brain injury (TBI)}

Moderate and extreme TBIs build the danger of building up Alzheimer's malady and different dementias. TBI is the disturbance of typical mind capacity brought about by a blow or shock to the head or entrance of the skull by a remote article. Not all blows or shocks to the head disturb cerebrum capacity. Moderate TBI is characterized as a head harm bringing about loss of cognizance or post-traumatic amnesia that keeps going over 30 minutes. On the off chance that loss of cognizance or posttraumatic amnesia keeps going over $24 \mathrm{hrs}$, the damage is viewed as extreme. Half of all moderate and extreme TBIs are brought on by engine vehicle mishaps. Moderate TBI is connected with double the danger of building up Alzheimer's and different dementias contrasted and no head wounds, and extreme TBI is connected with 4.5 times the danger. People who have encountered rehashed head wounds, for example, boxers, football players, and battle veterans are at higher danger of dementia, intellectual disability, and neurodegenerative ailment than people who have not experienced head damage. Proof proposes that even rehashed gentle TBI may advance neurodegenerative sickness. Some of these neurodegenerative ailments, for example, unending traumatic encephalopathy, must be recognized from Alzheimer's upon dissection.

\section{Genetic}

There is likewise hereditary issue including hazard variable for Alzheimer's sickness. The vast majority of patient builds up Alzheimer's illness after 70 ages. In any event, half of these early onset patients having acquired quality changes connected with their Alzheimer's sickness. Normal certain qualities build the danger of creating Alzheimer illness. In human, apoE quality was separated into three distinct structures i.e.

- ApoE2

- ApoE3

- ApoE4.
ApoE4 quality was connected with expanded danger of Alzheimer's sickness. The recurrence of the ApoE4 form of the quality in the allinclusive community changes.

\section{Estrogen}

The vast majority of the clinical study gives or found that female has a higher danger for Alzheimer's sickness than male. It is positively genuine that female live more than male, however, age alone does not appear to clarify the expanded recurrence in female. Late studies recommend that estrogen ought not be endorsed or regulated to postmenopausal female with the end goal of diminishing the danger of Alzheimer's sickness.

\section{PREVENTION}

There are no demonstrated approaches to keep the advancement of Alzheimer's infection. Nonetheless, there is epidemiological proof to recommend that driving a solid way of life can diminish the danger of Alzheimer's infection. Cardiovascular danger elements such as hypertension, diabetes, and smoking give higher danger of onset Alzheimer malady. This malady cannot avoid by cholesterol bringing down medication. Standard physical action and practice may have a general defensive impact on cerebrum well-being and may moderate movement of Alzheimer's malady. In spite of the fact that there are no particular dietary determinations for Alzheimer's, a Mediterraneanstyle diet (i.e. plant nourishments, for example, vegetables, natural products, beans, entire grains, nuts, olives and olive oil, alongside a few cheeses, yogurt, fish, poultry, and eggs) may lessen the danger of Alzheimer's infection. Another preventive choice is scholarly movements such as perusing, playing prepackaged game, playing musical instrument, and social association likewise demonstrates a diminished danger for Alzheimer infection. Individuals who eat sound nourishment have a lower danger of Alzheimer ailment. At the point, when eating regimen containing high soaked fats and basic starches such as monosaccharide and disaccharide, then it gives higher danger of Alzheimer illness. Another eating routine containing Mediterranean eating regimen was useful cardiovascular impact. Number of sustenance containing high grouping of flavonoids such as cocoa, red wine, and tea can likewise diminish the danger of Alzheimer ailment. Vitamins such as vitamin $\mathrm{A}$ and vitamin $\mathrm{C}$ and minerals such as zinc, selenium, and folic corrosive give no impact on well-being or do not declines or builds the danger of Alzheimer malady. At the point, when patient having long-term utilization of NSAID, i.e., non-steroidal mitigating drugs gives with a lessened probability of growing AD. Individuals who take part in scholarly exercises such as perusing, tabletop games, playing musical instrument, and social cooperation give decrease of Alzheimer's sickness hazard. Physical action additionally diminished danger of Alzheimer ailment. Individuals who lunch or supper or eat a sound, Japanese or Mediterranean eating regimen having lower danger of Alzheimer ailment. Immersed fats and basic starches diet give higher danger of Alzheimer infection. There is constrained confirmation that utilization of liquor, especially red wine, gives lower danger of Alzheimer infection. There is provisional proof that caffeine might ensure danger of Alzheimer sickness. Various nourishments with high convergence of flavonoids such as cocca, red wine, and tea may diminish the danger of Alzheimer infection [27-30].

\section{DIAGNOSIS}

There is a no single test to diagnose Alzheimer's disease. Diagnosis involves a full assessment of medical and psychiatric history to rule out other possible causes. Therefore, a variety of tests are required to obtain a conclusive diagnosis, which may like (Table 3).

\section{TREATMENT}

\section{Pharmacologic treatment}

Pharmacologic medicines utilize pharmaceutical to moderate or stop a disease or treat its manifestations. Six medications have been affirmed by the U.S. Nourishment and Drug Administration (FDA) that briefly 
enhance side effects of Alzheimer's sickness by expanding the measure of chemicals called neurotransmitters in the cerebrum. The viability of these medications shifts from individual to individual. In any case, none of the medicines accessible today for Alzheimer's malady moderates or stops the harm to neurons that cause Alzheimer's side effects and in the end makes the ailment lethal. In December 2014, the FDA affirmed the $6^{\text {th }}$ medication, which consolidates two existing FDA-endorsed Alzheimer's medications and is for moderate to the serious malady. Preceding that, the last endorsement of an Alzheimer's medication was in 2003. In the decade of 2002-2012, 244 medications for Alzheimer's were tried in clinical trials enrolled with ClinicalTrials.gov, a National Institutes of Health registry of freely and secretly financed clinical studies. The medication affirmed in 2003 was the main medication of the 244 tried to finish the clinical trials handle and get endorsement. Numerous variables add to the trouble of creating compelling medications for Alzheimer's. These components incorporate the high cost of medication improvement, the moderately long time expected to watch ailment movement in Alzheimer's, and the structure of the cerebrum, which is secured by the blood-mind obstruction, through which few medications can cross [31-35].

\section{Non-pharmacologic therapy}

Non-pharmacologic treatments are those that utilize approach other than prescription, for example, music treatment and memory (treatment in which photographs and other recognizable things might be utilized to inspire review). Likewise, with flow pharmacologic treatments, non-pharmacologic treatments have not been appeared to modify the course of Alzheimer's infection. Non-pharmacologic treatments are regularly utilized with the objective of keeping up or enhancing psychological capacity, the capacity to perform exercises of day by day living, or general personal satisfaction. They additionally might be utilized with the objective of diminishing behavioral side effects, for example, melancholy, aloofness, meandering, rest aggravations, tumult, and hostility. Deliberate surveys of distributed examination on non-pharmacologic treatments have observed that a few, for example, exercise and intellectual action (for instance, planting, word amusements, listening to music, and cooking) show guarantee. Be that as it may, few non-pharmacologic treatments have been tried in randomized controlled studies, which give the most grounded proof of whether a treatment is compelling. In randomized controlled studies, members are haphazardly allocated to get treatment or not get treatment, and results from the two gatherings are thought about. Extra research on non-pharmacologic treatments is expected to better assess their viability. Alzheimer malady was analyzed in view of the patient's medicinal history, history from relative and by behavioral perception. This Alzheimer illness additionally determined to have registered tomography, attractive reverberation imaging, i.e., X-ray and single photon emanation figured tomography or positron discharge tomography. As there is no known cure for Alzheimer's ailment, treatment concentrates on overseeing manifestations and supporting the individual and their family. This may include: Medications such as dozing tablets furthermore sedatives [35]. They may control side effects such as restlessness and disturbance. Cholinesterase inhibitors have demonstrated some viability. These pharmaceuticals likewise keep the breakdown of acetylcholine. Acetylcholine goes about as neurotransmitter in charge of memory. Cholinesterase inhibitors are likewise accessible as meds in New Zealand incorporate (donepezilrex), rivastigmine (exelon), and galantamine (reminyl). Memantine medication was all the more as of late found and utilized as a part of the treatment Alzheimer's infection. Memantine medication is likewise accessible in New Zealand. Memantine works distinctively to the cholinesterase inhibitors. Memantine medication is utilized to keep the passage of an abundance measure of calcium into cerebrum cells [36]. More elevated amount of calcium in the cerebrum cells causes harm to them, furthermore keeps them from accepting signs from other mind cells. Presently, donepezil is the main medication that is government sponsored for the treatment of Alzheimer's ailment. Research proceeds into the improvement of different pharmaceuticals for the treatment of Alzheimer's malady. Inquire about likewise proceeds into the utilization of option treatments, for example, against oxidants such as Vitamin E, selenium, and some home grown concentrates [37].

\section{CLASSIFICATION OF ANTI-ALZHEIMER'S DRUG}

Anti-Alzheimer's disease can be classified into various types. They are as follows:

Table 3: Diagnosis of Alzheimer disease

\begin{tabular}{ll}
\hline S. No. & Diagnosis \\
\hline 1 & A neurological and physical examination \\
2 & Brain scans \\
3 & Blood and urine tests \\
4 & Mental status assessment to determine the level of \\
& mental deterioration \\
5 & Caregiver interview to determine the level of dependency \\
6 & Scans to check brain structure and function may be \\
7 & recommended \\
& The different types of scans used may include CT scanning \\
& and MRI
\end{tabular}

CT: Computerized tomography, MRI: Magnetic resonance imaging

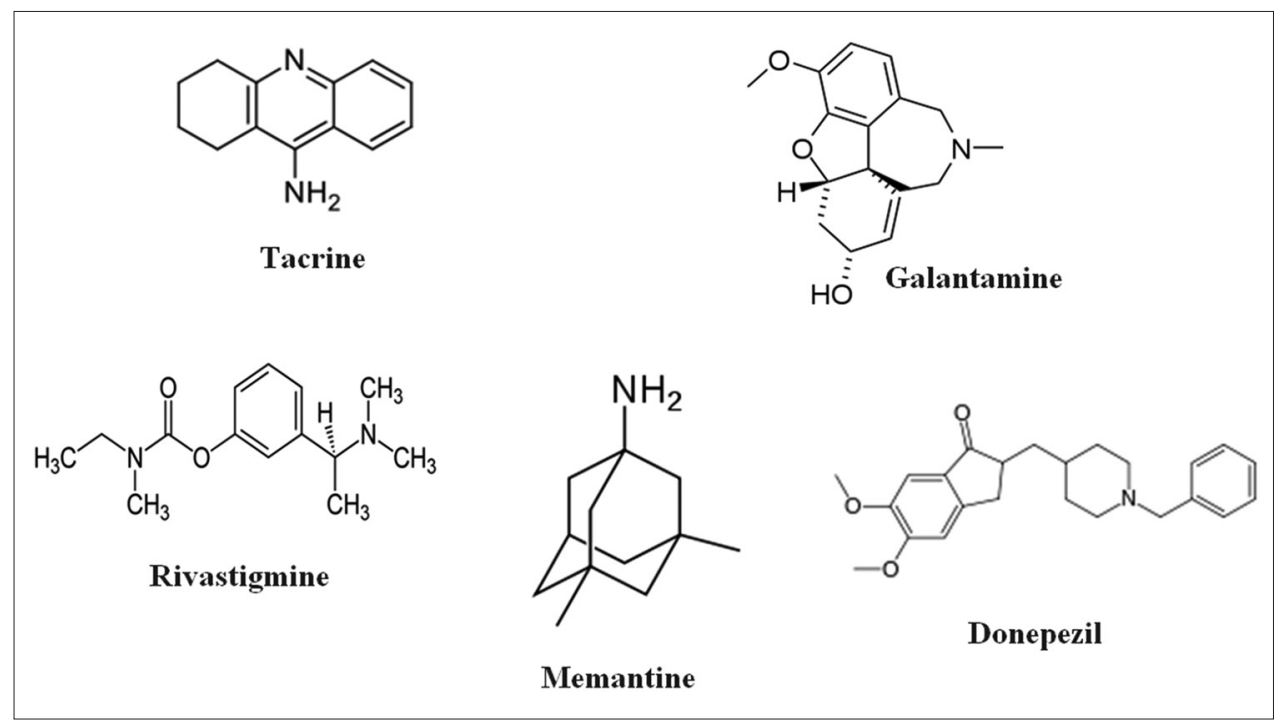

Fig. 2 
A. Cholinesterase inhibitors,

B. Partial glutamate antagonist.

\section{Cholinesterase inhibitors}

Neurotransmitter-like acetylcholine is compound flag-bearers delivered by nerves that the nerves use for speaks with each other so as to complete their capacities. Neurotransmitter is crucial for mind action. At the point, when less measure of Neurotransmitter was created in the mind then Alzheimer's malady was happened. Acetylcholine is critical and vital for or in the capacity to frame new recollections. Cholinesterase inhibitors are utilized for aversion or obstructing the breakdown of acetylcholine. Thus, more acetylcholine is accessible or delivered in the mind, and it can get to be less demanding to frame new recollections [38]. All cholinesterase inhibitors are affirmed by the United States of Food and Drug Administration. Case of cholinesterase inhibitors are:

- Donepezil

- Rivastigmine

- Galantamine

- Tacrine.

Rivastigmine and galantamine are just endorsed by the FDA for mellow to direct Alzheimer's sickness and donepezil is affirmed for gentle, moderate, and serious Alzheimer's ailment. galantamine was utilized as a part of the treatment of extreme Alzheimer ailment. Cholinesterase inhibitors give likewise symptoms such as sickness, heaving, muscles spasm, and loose bowels.

\section{Partial glutamate rival}

Another neurotransmitter in the cerebrum is glutamate. More measure of glutamate in cerebrum cause crumbling of nerve cells. Case of incomplete glutamate foe is Memantine $[39,40]$. Memantine repress or diminishes the impact of glutamate to actuate nerve cells. This medication is utilized as a part of the treatment of moderate to extreme dementia. This medication was affirmed by the U.S. FDA for the treatment of moderate to serious dementia (Fig. 2).

\section{REFERENCES}

1. Baddeley AD, Hitch GJ. Working memory. In: Bower GH, editor. The Psychology of Learning and Motivation. Vol. 8. New York: Academic Press; 1974. p. 47-89.

2. Baddeley A. Working memory: Theories, models, and controversies. Annu Rev Psychol 2012;63:1-29.

3. Mikels JA, Reuter-Lorenz PA, Beyer JA, Fredrickson BL. Emotion and working memory: Evidence for domain-specific processes for affective maintenance. Emotion 2008;8(2):256-66.

4. Schmeichel BJ, Volokhov RN, Demaree HA. Working memory capacity and the self-regulation of emotional expression and experience. J Pers Soc Psychol 2008;5(6):1526-40.

5. Mammarella N, Borella B, Carretti B, Leonardi G, Fairfield B. Examining an emotion enhancement effect in working memory: Evidence from age-related differences. Neuropsychol Rehabil 2013;23(3):416-28.

6. Mikels JA, Larkin GR, Reuter-Lorenz PA, Carstensen LL. Divergent trajectories in the aging mind: Changes in working memory for affective versus visual information with age. Psychol Aging 2005;20(4):542-53.

7. Mather M. Aging and emotional memory. In: Reisberg D, Hertel P, editors. Memory and Emotion. NY: Oxford University Press; 2004. p. 272-307.

8. Gazzaley A, Sheridan MA, Cooney JW, D’Esposito M. Age-related deficits in component processes of working memory. Neuropsychology 2007;21(5):532-9.

9. Schultz RR, de Castro CC, Bertolucci PH. Memory with emotional content, brain amygdala and Alzheimer's disease. Acta Neurol Scand 2009;120(2):101-10.

10. Satler C, Tomaz C. Emotional working memory in Alzheimer's disease patients. Dement Geriatr Cogn Dis Extra 2011;1(1):124-38.

11. Dohnel K, Sommer M, Ibach B, Rothmayr C, Meinhardt J, Hajak G. Neural correlates of emotional working memory in patients with mild cognitive impairment. Neuropsychologia 2008;46(1):37-48.
12. Fleming K, Kim SH, Doo M, Maguire G, Potkin SG. Memory for emotional stimuli in patients with Alzheimer's disease. Am J Alzheimers Dis Other Demen 2003;18(6):340-2.

13. Boller F, El Massioui F, Devouche E, Traykov L, Pomati S, Starkstein SE. Processing emotional information in Alzheimer's disease: Effects on memory performance and neurophysiological correlates. Dement Geriatr Cogn Disord 2002;14(2):104-12.

14. Huijbers MJ, Bergmann HC, Rikkert MG, Kessels RP. Memory for emotional pictures in patients with Alzheimer's dementia: Comparing picture-location binding and subsequent recognition. J Aging Res 2001;2011:9.

15. Borg C, Leroy N, Favre E, Laurent B, Thomas-Anterion C. How emotional pictures influence visuospatial binding in short-term memory in ageing and Alzheimer's disease? Brain Cogn 2011;76(1):20-5.

16. Nashiro K, Mather M. Effects of emotional arousal on memory binding in normal aging and Alzheimer's disease. Am J Psychol 2011;124(3):301-12.

17. Daneman $\mathrm{M}$, Carpenter PA. Individual differences in working memory and reading. J Verbal Learning Verbal Behav 1980;19(4):450-66.

18. Engle RW, Kane MJ. Executive attention, working memory capacity, and a two factor theory of cognitive control. In: Ross BH, editor. The Psychology of Learning and Motivation. Vol. 44. San Diego: Academic Press; 2006. p. 145-99.

19. Mammarella N, Fairfield B, De Leonardis V, Carretti B, Borella E, Frisullo E, et al. Is there an affective working memory deficit in patients with chronic schizophrenia? Schizophr Res 2012;138(1):99-101.

20. Turner ML, Engle RW. Is working memory capacity task dependent? J Mem Lang 1989;28(2):127-54.

21. Doninger NA, Bylsma FW. Inhibitory control and affective valence processing in dementia of the Alzheimer type. J Neuropsychol 2007; 1:65-83.

22. Mather M, Knight M. Goal-directed memory: The role of cognitive control in older adults' emotional memory. Psychol Aging 2005;20(4):554-70.

23. Kensinger EA, Corkin S. Effect of negative emotional content on working memory and long-termmemory. Emotion 2003;3(4):378-93.

24. Henry JD, Rendell PG, Scicluna A, Jackson M, Phillips LH. Emotion experience, expression, and regulation in Alzheimer's disease. Psychol Aging 2009;24(1):252-7.

25. Goodkind MS, Gyurak A, McCarthy M, Miller BL, Levenson RW. Emotion regulation deficits in frontotemporal lobar degeneration and Alzheimer's disease. Psychol Aging 2010;25(1):30-7.

26. Winecoff A, Labar KS, Madden DJ, Cabeza R, Huettel SA. Cognitive and neural contributors to emotion regulation in aging. Soc Cogn Affect Neurosci 2011;6(2):165-76.

27. LaBar KS, Cabeza R. Cognitive neuroscience of emotional memory. Nat Rev Neurosci 2006;7(1):54-64.

28. Watanabe M, Hikosaka K, Sakagami M, Shirakawa S. Reward expectancy-related prefrontal neuronal activities: Are they neural substrates of "affective" working memory? Cortex 2007;43(1):53-64.

29. D'Esposito M, Postle BR, Rypma B. Prefrontal cortical contributions to working memory: Evidence from event-related fMRI studies. Exp Brain Res;133(1):3-11.

30. Mather M, Canli T, English T, Whitfield S, Wais P, Ochsner K, et al. Amygdala responses to emotionally valenced stimuli in older and younger adults. Psychol Sci 2004;15(4):259-63.

31. Kensinger EA, Schacter DL. Neural processes supporting young and older adults' emotional memories. J Cogn Neurosci 2008;20(7):1161-73.

32. Klein-Koerkamp Y, Baciu M, Hot P. Preserved and impaired emotional memory in Alzheimer's disease. Front Psychol 2012;3:331.

33. Horínek D, Varjassyová A, Hort J. Magnetic resonance analysis of amygdalar volume in Alzheimer's disease. Curr Opin Psychiatry 2007;20(33):273-7.

34. Poulin SP, Dautoff R, Morris JC, Barrett LF, Dickerson BC. Amygdala atrophy is prominent in early Alzheimer's disease and relates to symptom severity. Psychiatry Res Neuroimag 2011;194(1):7-13.

35. Perrin M, Henaff MA, Padovan C, Faillenot I, Merville A, KrolakSalmon P. Influence of emotional content and context on memory in mild Alzheimer's disease. J Alzheimers Dis 2012;29:817-26.

Rosenbaum RS, Furey ML, Horwitz B, Grady CL. Altered connectivity among emotion-related brain regions during short-term memory in 
Alzheimer's disease. Neurobiol36. Aging 2010;31(5):780-6.

37. Mammarella N, Fairfield B, De Beni R, Cornoldi C. Aging and intrusion errors in an active visuo-spatial working memory task. Aging Clin Exp Res 2009;21(4-5):282-91

38. Allen RJ, Baddeley AD, Hitch GJ. Is the binding of visual features in working memory resource-demanding? J Exp Psychol Gen 2006; $135: 298-313$
39. Kensinger EA, Anderson A, Growdon JH, Corkin S. Effects of Alzheimer disease on memory for verbal emotional information. Neuropsychologia 2004;42(6):791-800.

40. Forsteimer S, Maercker A, Maier W, van den Bussche H, RiedelHeller S, Riedel-Heller S, et al. Motivational reserve: Motivationrelated occupational abilities and risk of mild cognitive impairment and Alzheimer disease. Psychol Aging 2012;27(2):353-63 . 